\title{
Development of explosive breaking principles for the ores prone to overgrinding
}

\author{
Artem Rozhkov*, Igor Sokolov, Yuri Antipin and Kirill Baranovsky \\ Institute of Mining of the Ural branch of the Russian Academy of Sciences, Laboratory of \\ Underground Geotechnology, 620075, Ekaterinburg, Russia
}

\begin{abstract}
In underground mining of valuable non-metallic raw materials, non-ferrous and precious metal ores, the problem of overgrinding of raw materials as a result of blasting operations is quite acute. For ores of nonferrous and precious metals, represented by strong rocks, the effect of increased concentration of ore minerals in small classes of ore is characteristic. Due to the process of segregation of the mass in ore drawing, small fractions accumulate in significant quantities on the lying side of the mine goaf and on the roughness of its surface. Such ore is often simply lost. It is rational to create conditions for reducing the yield of small fractions already at the stage of separating the ore from the array. Therefore, the development of technological methods for managing the quality of mining enterprise products and methods for improving the completeness of extracting mineral reserves is an urgent scientific and technical task. To solve this problem, a number of model and full-scale experiments were conducted to identify the dependence of the nature of destruction on the method and parameters of blasting, followed by statistical evaluation of the results. The principles of determining the parameters of the technology for breaking valuable ores that are prone to overgrinding are established.
\end{abstract}

Keywords: overgrinding, detonation products, main crack, flat system, line of least resistance, convergence coefficient

\section{Introduction}

In underground mining of valuable non-metallic raw materials, non-ferrous and precious metal ores, the problem of overgrinding of raw materials as a result of blasting operations is quite acute. Overgrinding of valuable non-metallic raw materials leads to an actual decrease in the yield of concentrates or final products, due to sufficiently strict requirements of the mineral processing technology for the pieces conditioned size and structural safety of useful component. For ores of non-ferrous and precious metals, represented by strong rocks, the effect of increased concentration of ore minerals in small classes of ore is characteristic. [1]. Due to the process of segregation [2] of the mass in ore drawing, small fractions accumulate in significant quantities on the lying side of the mine goaf and on the roughness of its surface. Such ore, with an increased content of a useful

\footnotetext{
*Corresponding author: geotech@igduran.ru
} 
component, requires additional technological measures for its extraction or is simply lost. In both cases, the economic efficiency of underground geotechnology is reduced. Therefore, the development of technological methods for managing the quality of mining enterprise products and methods for improving the completeness of extracting mineral reserves in underground mining systems without the presence of people in the open mine goaf is an urgent scientific and technical task.

\section{Materials and Methods}

The significant strength of the ores and rocks of the deposits under consideration determines the use of an explosive method of breaking. In underground mining of ore deposits, the main method of blasting operations is blasthole ring breaking with charges of a solid structure. To reduce the yield of oversized ore, long-delay and short-delay blasting devices are used. It is known that in the near zone of the explosion, mainly fine particles (less than $1 \mathrm{~mm}$ ) are formed, and in the explosion of elongated charges in brittle rock, the main volume of destruction falls on the zone of radial cracking. Since the size of small fractions, also subject to the effect of segregation, exceeds the size of particles formed in the zone of fine crushing, the source of their yield is also the zone of radial cracks [3]. The use of long-delayed and short-delayed blasting necessarily leads to significant energy consumption for grinding in the near zone, multiple loads of the array, the development of additional cracks from the explosions of neighboring charges, and intense collision of ore pieces during their scattering. Therefore, it is necessary to create conditions under which the development of zones of grinding and radial cracking will be suppressed.

The use of an instantaneous method of blasting with certain design parameters of the location of blastholes and charges in them, allows us to minimize the size of the grinding zones around the charges due to the advanced formation of the main crack along the plane of the location of charges [4-6]. This method of blasting is applicable if the ores have a natural or induced fracturing, and the size of the separateness does not exceed the size of the conditioned ore piece. The development of the zone of radial cracks depends on the design parameters of the location of blastholes in blasthole ring. In this case, the layer is split along natural cracks under the action of detonation products in the resulting slit-like cavity. Therefore, it is sufficient to separate the breaking layer from the array [7].

The design parameters of the blasthole ring charges should ensure the rapid growth of the main crack along the plane of the blastholes location. The first condition is that the distance between the ends of the blastholes $(a)$ corresponds to the possible breakdown distance between them $a_{\min } \leq a \leq a_{\max }$, that is, the physical possibility of interaction of charges with each other in the rock under consideration [8]. The second condition is the advance growth of the separation crack, before radial cracks develop to the free surface, or transverse shear cracks. In [4], for fractured iron ores of the Ural deposits, provided that the energy of the reflected wave is preserved in the breaked layer, it is determined that the parameters should correspond to

$$
\left.\begin{array}{r}
\frac{W}{v_{t s c}}>\frac{W}{C_{p}}+\frac{0.5 a}{v_{n s c}} \\
\frac{2 W}{C_{p}}>\frac{0.5 a}{v_{n s c}}
\end{array}\right\},
$$

where $W$ - line of least resistance, $\mathrm{m} ; a$ - distance between charges, $\mathrm{m} ; C_{p}$ - longitudinal wave speed, $\mathrm{m} / \mathrm{s} ; v_{t s c}, v_{n s c}$ - the rate of development of transverse shear cracks and normal separation, respectively, $\mathrm{m} / \mathrm{s}$. 
If condition (1) is met, the charge convergence coefficient (m), depending on the orientation of the crack systems in the array relative to the plane of the charges, will be from 0.6 to 0.9 . In addition to a significant drilling expense, conditions will be created under which it is quite difficult to achieve a reduced specific consumption of explosive. Since it is only enough to separate the layer from the array, you should not strive to preserve the energy of the reflected wave. Then, the condition under which the main crack will develop before radial cracks and transverse shear cracks is written as follows

$$
\frac{W}{v_{t s c}}>\frac{0.5 a}{v_{n s c}}, \mathrm{~s} .
$$

Since line of least resistance and distance between charges are connected by the convergence coefficient $(m)$, it is possible to define $m$ at which condition (2) will be satisfied. The convergence coefficient in this case is a self-valuable indicator that largely determines the speed at which either the separating of the breaking layer will occur, or its advanced destruction by radial cracks to the free surface with the formation of a characteristic zone of fine crushing in the near zone of the explosion around the charges.

Another condition for breaking ores prone to overgrinding is the separation of the layer with the lowest possible energy consumption. A characteristic value in this case is the pressure on the walls of the combined slit-like cavity $\left(P_{s l c}\right)$ in the zone of the blasthole faces, since it is there that the lowest specific consumption of explosives due to the largest distance between charges.

The pressure in the slit-like cavity is determined by transforming prof. F.A. Baum's formula for the average initial pressure of detonation products, taking into account the character of the interaction and design parameters of the group of charges in the blasthole ring, and is presented as a dependence on the distance between charges at their different diameters

$$
P_{s l c}=0.5 \frac{\rho_{\exp } D^{2}}{(i+1)}\left(\frac{n \pi r^{2}}{n \pi r_{k}^{2}+2 \Delta u B_{\mathrm{\kappa}}}\right)^{i}, \mathrm{MPa}
$$

где $\rho_{\text {exp }}$ - density of explosives in the charge, $\mathrm{kg} / \mathrm{m}^{3} ; D$ - explosive detonation speed, $\mathrm{m} / \mathrm{s}$; $i$ - index of polytropes of explosive gases; $n$ - number of blastholes in the ring, pc.; $r$ - the radius of the charge, $\mathrm{m} ; r_{k}$ - the established radius of the blasthole cavity, $\mathrm{m}$; $\Delta u$ - the value of the displacement of the wall of the slit-like cavity, $\mathrm{m} ; B_{\mathrm{K}}$ - blasthole ring width at the ends of blastholes, $\mathrm{m}$.

It is obvious that the separation of the layer will occur at some minimum necessary pressure $\left(P_{\mathrm{min}}\right)$ on the walls of the cavity. Therefore, according to the criterion of ensuring the separation of the layer and the minimum possible impact on the array, the design parameters of breaking should provide $P_{s l c} \geq P_{\min }$ at $P_{s l c} \rightarrow P_{\min }$. Then, the compliance of the design parameters of breaking technology with the combined performance of which ensures the minimization of the size of the grinding zones and radial cracking, is written as follows

$$
\left\{\begin{array}{l}
a_{\min } \leq a \leq a_{\max } \\
m=\frac{a}{W} \leq x, x \rightarrow \frac{W}{v_{t s c}}>\frac{0,5 a}{v_{n s c}} \\
P_{s l c} \geq P_{\min }, P_{s l c} \rightarrow P_{\min }
\end{array}\right.
$$




\section{Results and Discussion}

The corresponding calculations were performed on the example of the Kyshtym deposit of granulated quartz $(f=12)$. For the breakdown distance from $a_{\min }$ to $a_{\max }$, the pressure in the slit-like cavity in the area of blasthole faces at a charge radius of $65 \mathrm{~mm}$ will be 240 $160 \mathrm{MPa}$ (Fig. 1). Given the value of $a_{\max }$, the distance between the ends of blastholes for all lines of least resistance with this diameter of charges should not be more than $2.7 \mathrm{~m}$. Sufficient for separation, the pressure of detonation products in the slit-like cavity is achieved at a value of 2.4-2.5 m. The rational convergence coefficient is 1.2-1.4. With a charge radius of $105 \mathrm{~mm}$, the pressure of detonation products in the slit-like cavity is more than $300 \mathrm{MPa}$. Their use is not rational.

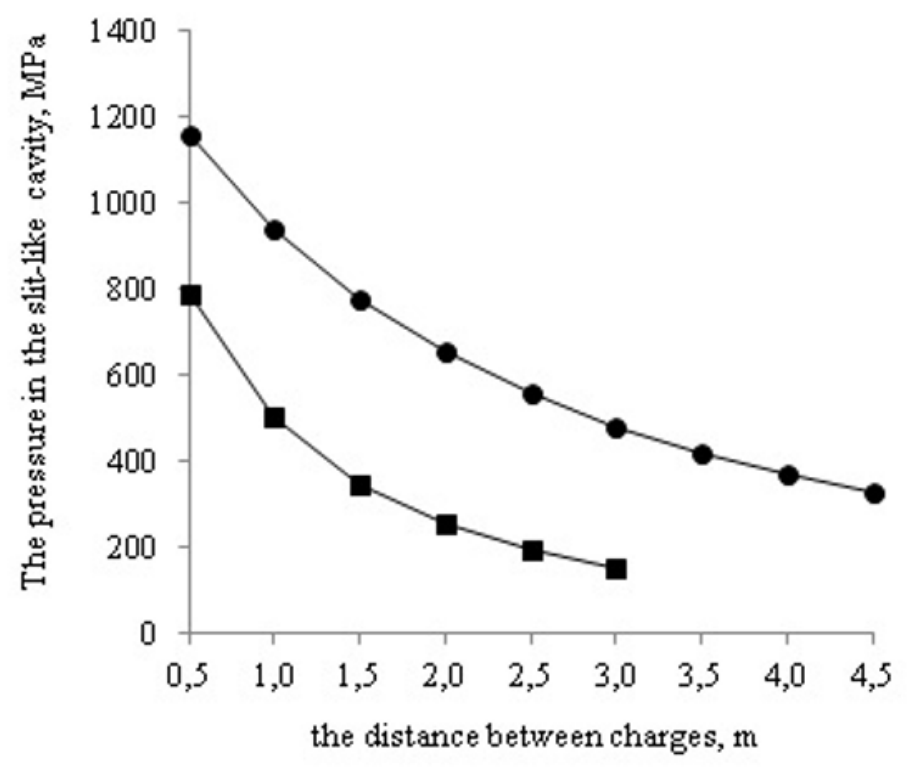

$\rightarrow$ charge diam etr $=65 \mathrm{~mm} \rightarrow-$ charge diam etr $=105 \mathrm{~mm}$

Fig. 1. Dependence of the pressure in the slit-like cavity on the distance between charges

In order to identify the character of the destruction of the array with various methods of blasting (instantaneous, short-delay, single charge) of a group of elongated charges, depending on their convergence coefficient, a physical simulation of explosive breaking was performed. 45 quartz-cement and 1 quartz sample were blasted. The influence of the method of explosion on the character of destruction in the near zone of explosion was determined from the sample $n=46$ [9].

For the null hypothesis, the position was taken that the use of delayed and short-delayed methods of blasting is associated with the formation of a grinding zone around the charges. The method of blasting (feature 1) and overgrinding in the near zone (feature 2) are presented in the form of a table of conjugacy of features (table 1), where $(+)$ and $(-)$ the presence or absence of the feature, respectively.

The relationship between the features was established using the Pearson tetrachoric conjugacy coefficient, which is determined by [10]

$$
r_{a}=\frac{a d-b c}{\sqrt{(a+b)(c+d)(a+c)(b+d)}} .
$$


In this example

$$
r_{a}=\frac{25 \cdot 19-2 \cdot 0}{\sqrt{27 \cdot 19 \cdot 25 \cdot 21}}=0.915
$$

To test the null hypothesis, we use the Pearson $\chi$-criterion defined

$$
\chi^{2}=n r_{a}^{2} .
$$

As a result, we get

$$
\chi^{2}=46 \cdot 0.915^{2}=38.5
$$

Table 1. Conjugacy of features for $n=46$

\begin{tabular}{|c|c|c|c|}
\hline \multirow{2}{*}{$\begin{array}{c}\text { Overgrinding in } \\
\text { the near } \\
\text { explosion zone }\end{array}$} & \multicolumn{2}{|c|}{ long-delay and short-delay blasting method } & \multirow{2}{*}{$\Sigma$} \\
\cline { 2 - 3 } & $(+)$ & $(-)$ & \\
\hline$(+)$ & $a=25$ & $b=2$ & $a+b=27$ \\
\hline$(-)$ & $c=0$ & $d=19$ & $c+d=19$ \\
\hline & $a+c=25$ & $b+d=21$ & $n=46$ \\
\hline
\end{tabular}

Comparison of the calculated value with the critical $\chi_{\alpha}^{2}$ at the significance level $\alpha=0.05$ $\left(\chi^{2} 0.05=3.84\right)$ shows $\chi^{2}>>\chi^{2} 0.05$, which allows us to conclude that there is a statistically significant relationship between the considered features. Thus, the feasibility of using an instantaneous method of explosion is confirmed.

It is theoretically determined that the growth of radial cracks is suppressed under the condition that convergence coefficient $m \leq 1.4$. The determination of the conjugacy of the accepted features $-m \leq 1.4$ (1) and the development of radial cracks to the free surface (2) was carried out for experiments with exploding blocks instantly, sample $n=21$. (table 2).

Table 2. Conjugacy of features for $\mathrm{n}=21$

\begin{tabular}{|c|c|c|c|}
\hline $\begin{array}{c}\text { Development of radial } \\
\text { cracks }\end{array}$ & $(+)$ & $(-)$ & \multirow{2}{|c|}{\begin{tabular}{c} 
\\
\cline { 2 - 4 }$(+)$
\end{tabular}} \\
\hline$(-)$ & $a=1$ & $b=10$ & $a+b=11$ \\
\hline & $a+c=9$ & $d=1$ & $c+d=10$ \\
\hline & $a+c=10$ & $n=21$ \\
\hline
\end{tabular}

In this case, the Pearson conjugacy coefficient is equal to

$$
r_{a}=\frac{1 \cdot 1-10 \cdot 9}{\sqrt{11 \cdot 10 \cdot 10 \cdot 11}}=-0.809
$$

Then, the Pearson $\chi$-criterion is equal to

$$
\chi^{2}=21 \cdot\left(-0.809^{2}\right)=13.7 .
$$

Comparison of the calculated value with the critical $\chi_{\alpha}^{2}$ at the significance level $\alpha=0.05$ $\left(\chi^{2} 0.05=3.84\right)$ allows us to conclude that there is a significant relationship between the convergence coefficient of charges in the zone of blasthole faces of the blasthole ring and the development of the zone of radial cracking at instantaneous explosion for the sample $n=21$. 
In the field conditions of the Kyshtym underground mine, experimental studies of the instantaneous blasting technology with various design parameters blasthole ring charges were conducted (table 3 ).

Table 3. The parameters of experimental explosions

\begin{tabular}{|c|c|c|c|c|c|c|}
\hline no. & Charge design & $W, \mathrm{~m}$ & $a, \mathrm{~m}$ & $m$ & $q_{\exp }$ & $L_{a g} / L_{\text {chrg }}$ \\
\hline 1 & Solid & 1.6 & 2.2 & 1.4 & 1.55 & 0 \\
\hline 2 & & 1.6 & 2.2 & 1.4 & 1.20 & 0.24 \\
\cline { 1 - 6 } 3 & \multirow{3}{*}{ Dispersed } & 1.7 & 2.4 & 1.4 & 0.98 & 0.48 \\
\cline { 3 - 7 } & & 1.6 & 2.2 & 1.4 & 0.92 & 0.13 \\
\cline { 3 - 7 } & & 1.8 & 2.2 & 1.2 & 0.90 & 0.44 \\
\hline 5
\end{tabular}

Five experimental explosions were performed to determine the effect of charge dispersion parameters on the quality of crushing. The blasthole ring charges with instantaneous blasting technology explosion are considered by us as a single flat system.

A complete separation of all five layers was achieved, which was confirmed by the results of volumetric laser scanning of the developed space. The deviation of the target and chamber contours from the design values is within the acceptable limits $-2-10 \%$. Analytical dependences of the yield of the overgrinding quartz fraction $(\gamma)$ on the parameters of the specific consumption of explosives $\left(q_{\exp }, R^{2}=0.84\right)$ and the parameters of charge dispersion in a flat system, expressed as the ratio of the sum of the air gap lengths to the sum of the explosive charge lengths in the blasthole ring $\left(L_{a g} / L_{c h r g}, R^{2}=0.92\right)$

$$
\left\{\begin{array}{c}
\gamma=23.86 q_{\text {exp }}-8.07 \\
\gamma=-27.04 \frac{L_{a g}}{L_{\text {chrg }}}+24.88
\end{array} .\right.
$$

It was found that the reduction of the yield of the quartz overgrinding fraction by 1.7 times relative to the traditional explosive breaking technology, which consisted in the longdelay blasting of charges with a diameter of $105 \mathrm{~mm}$ dispersed by an inert aggregate, is achieved by using a flat system of charges of a dispersed design with a specific consumption of explosives $0.9-1.0 \mathrm{~kg} / \mathrm{m}^{3}$ and the ratio of the lengths of air gaps to the lengths of charges of $0.44-0.48$.

\section{Conclusion}

The principles of determining the blasting technology parameters for strong ores that are prone to overgrinding are proposed. The conditions blasting, total fulfillment provides no minimum overgrinding in the near zone of the explosion - rapid growth of main cracks in the prescribed range, breakdown of the distances between neighboring charges with sufficient margin for the pressure of detonation products in the formed slit-like cavity.

The dependences of the yield of overgrinding fractions for conditions of the Kyshtym deposit of high-value granulated quartz, represented by strong fractured ores, are obtained. Since many deposits of non-ferrous and precious metals are represented by quartz veins, the results obtained can be considered quite indicative.

The research was carried out within the framework of the State Assignment No. 075-00581-1900. Topic No. 0405-2019-0005. 


\section{References}

1. G. G. Lomonosov, N. A. Tartygina, Mining. info-anal. bull., 6 (2014)

2. Yu. V. Laptev, Mine surv. and subsurf. use, 1 (2007).

3. R. Yang, C. Ding, L. Yang, Z. Lei, Z. Zhang, Y. Wang, IJRMMS, 112 (2018)

4. S. A. Gorinov, News of High. Inst. Mining Journ., 7 (1985)

5. A. V. Daneev, J. G. Dambaev, V. N. Kovalevsky, JHMT, 1, 14 (2017)

6. V. V. Adushkin, G. G. Kocharian, I. V. Brigadin, S. A. Krasnov, Mining. info-anal. bull., $7(2015)$

7. V. N. Kalmykov, V. Kh. Pergament, S. S. Neugomonov, Vestnik of Nosov Magnitogorsk State Technical University, 1 (2009)

8. Z. Yue, S. Tian, Z. Chen, Chin. Jour. RME, 37 (2018)

9. I. V. Sokolov, A. A. Smirnov, Yu. G. Antipin, A. A. Rozhkov, Vestnik of Nosov Magnitogorsk State Technical University, 1 (2017)

10. L. N. Savina, A. V. Popyrin, SWorld, 2 (2013) 